\title{
Derivas acadêmicas em pós-graduação em artes na cidade do Rio de Janeiro
}

\author{
Academic Drifts in Post-Graduation in Arts in \\ the City of Rio de Janeiro \\ Derivas académicas en posgrado en artes en \\ la ciudad de Río de Janeiro
}

\author{
Livia Flores Lopes*, Michelle Farias Sommer ${ }^{* *}$
}

http://dx.doi.org/10.22409/poiesis.2033.217-236

\begin{abstract}
RESUMO: Desilha é uma plataforma de pesquisa e ação em arte e cidade, que inclui projeto de pesquisa e cursos regulares oferecidos pelo Programa de PósGraduação em Artes Visuais (PPGAV-EBA-UFRJ), sediado na Ilha do Fundão, onde se localiza a cidade universitária. O histórico da construção deste campus universitário reflete as dificuldades de assentamento e concretização do lugar da educação no Brasil, oscilando entre projeto oligárquico e regime autoritário, utopia e inacabamento. Reconhecendo a potência da universidade pública e gratuita como lugar de trocas e amplas transformações hoje, Desilha expandese e toma a cidade como palco para a construção de narrativas avessas à normatividade acadêmica, em uma cidade violentamente impactada pelo desmonte de políticas públicas e pelas consequências das reformas urbanas ocorridas entre a realização dos megaeventos Copa do Mundo (2014) e Olimpíadas (2016). Nessa direção, restaura forças vitais para empreender novas travessias em tempos de crise e ameaças à democracia no Brasil.
\end{abstract}

PALAVRAS-CHAVE: ilha; arte contemporânea; cidade; universidade

\footnotetext{
* Livia Flores Lopes é artista e doutora em Artes Visuais pela UFRJ. É professora associada da Escola de Comunicação da UFRJ. E-mail: livflores@gmail.com. Orcid: https://orcid.org/0000-0003-2408-9591

"Michelle Farias Sommer atua no ensino, pesquisa, curadoria e crítica de artes visuais. É pós-doutoranda em Linguagens Visuais no PPGAV/UFRJ, doutora em História, Teoria e Crítica de Arte com estágio doutoral junto à University of the Arts London/Central Saint Martins. É mestre em Planejamento Urbano e Regional e arquiteta e urbanista. E-mail: mihsommer@gmail.com. Orcid: https://orcid.org/0000-0002-8689-2622
} 
ABSTRACT: Desilha is a research and action platform in art and city, which includes a research project and regular courses offered by the Postgraduate Program in Visual Arts (PPGAV-EBA-UFRJ), based at Fundão Island, where the university city is located. The history of construction of this university campus reflects the difficulties of establish and concretization the place of education in Brazil, oscillating between oligarchic project and authoritarian regime, utopia and incompleteness. Recognizing the power of the public, free university as a place for exchanges and ample transformations, Desilha takes the city as a stage for the construction of narratives averse to academic normativity in a city violently impacted by the dismantling of public policies and the consequences of the urban reforms that took place between the mega-events of the World Cup (2014) and the Olympics (2016). At this direction, restores vital forces to undertake new crossings in times of crisis and threats to democracy in Brazil.

KEYWORDS: island; contemporary art; city; university

RESUMEN: Desilha es una plataforma de investigación y acción en arte y ciudad, que incluye proyecto de investigación y cursos regulares ofrecidos por el Programa de Postgrado en Artes Visuales (PPGAV-EBA-UFRJ), con sede en la Isla de Fundão, donde se ubica la ciudad universitaria. El histórico de la construcción del campus universitario refleja las dificultades de asentamiento y concreción del lugar de la educación en Brasil, oscilando entre proyecto oligárquico y régimen autoritario, utopía e inacabamiento. Reconocemos la potencia de la universidad pública y gratuita como lugar de intercambios y amplias transformaciones hoy, Desilha toma la ciudad como escenario para la construcción de narrativas al revés de la normatividad académica en una ciudad violentamente impactada por el desmonte de políticas públicas y por las consecuencias de las reformas urbanas ocurridas entre la realización de los megaeventos Copa del Mundo (2014) y Olimpiadas (2016). En esta dirección, restaura fuerzas vitales para emprender nuevas travesías en tiempos de crisis y amenazas a la democracia en Brasil.

PALABRAS CLAVE: isla; arte contemporáneo; ciudad; universidad

Como citar: LOPES, Livia Flores; SOMMER, Michelle Farias. Derivas acadêmicas em pós-graduação em artes na cidade do Rio de Janeiro. Poiésis, Niterói, v. 20, n. 33, p. 217-236, jan./jun. 2019. doi: http://dx.doi.org/10.22409/poiesis.2033.217-236

Poiésis, Niterói, v. 20, n. 33, jan./jun. 2019. 


\title{
Derivas acadêmicas em pós-graduação em artes na cidade do Rio de Janeiro
}

\author{
Nas civilizações sem barcos, os sonhos se esgotam, a \\ espionagem ali substitui a aventura e a polícia, os \\ corsários. \\ -- Michel Foucault
}

Entre ilha e desilha: a universidade ${ }^{1}$

Em desilha, palavra inventada, a figura da ilha: ilhas em geral, sobretudo as imaginárias ou aquelas que parecem ser, pois elas nos revelam claramente suas qualidades de protótipo de mundos possíveis; mas também ilhas em particular, como a Ilha do Fundão, sobre a qual se assenta o campus de uma das maiores universidades do Brasil, a Universidade Federal do Rio de Janeiro (UFRJ). Tendo ali sua sede - no contexto do Programa de PósGraduação em Artes Visuais da Escola de Belas Artes - DESILHA_projeto de pesquisa em arte e cidade propõe o prefixo des como convite ao reconhecimento do estar-emsituação-de-ilha, logo, à sua desnaturalização. Os 280 passos entre ilha e continente podem unir ou separar mundos. 
Ilhas tem limites, seja o mar ou qualquer outro meio do qual o que chamamos de ilha se destaca como "contornos contornados"2, como aponta Peter Sloterdijk (2006, p. 872). Com essa expressão, o filósofo assinala o caráter construtivo implicado na ideia de ilha, deslocando-a do campo dos fenômenos naturais para o de uma práxis que a reinterpreta segundo pressupostos técnicos, políticos ou poéticos.

Primeiro e fundamental movimento de desilha: reconhecer a ilha como uma espécie de moldura que a isola do contexto no qual se insere, interrompendo-Ihe a continuidade por meio da ação demarcadora que a constitui. "É a força demarcadora que traça um limite ao ímpeto sobressalente da ilha, como se essas superfícies sem contexto fossem uma espécie de obras de arte emergentes da natureza, que o mar cinge como fragmentos de exibição da natureza". (SLOTERDIJK, 2006, p. 799)

Em seu Dicionário de lugares imaginários, Alberto Manguel e Gianni Guadalupi listam 396 nomes de ilhas oriundos de obras literárias, que mal reconhecemos. Tampouco guardamos os nomes das ilhas percorridas por Ulisses em seu longo périplo de volta a Ítaca ou daquelas onde Próspero, Gulliver e Robinson Crusoé aportam ou onde Morel desenvolve seus estranhos experimentos entre imagem e vida. Mas fato é que a figura do náufrago parece ser solidária a da ilha. Eles nos revelam mundos idiossincráticos, seja por nos oferecerem visões do Outro desconhecido ou de nós mesmos, ao transportarem comsigo certos conjuntos de padrões culturais que reconhecemos como nossos, mesmo que deslocados no tempo.

Ilhas habitadas, imaginárias ou não, teriam assim a capacidade de nos revelar como outros-de-nós-mesmos, não como pura subjetividade, mas espelhando certas exterioridades que nos constituem enquanto seres sociais em condições particulares de espaço-tempo. Nesse sentido, ilhas são aqui entendidas como potências de figuração que extrapolam o âmbito geográfico para reverberar políticas - ou poéticas - que as constituem.

Podemos ainda pensar ilhas como heterotopias, a partir de indicação fornecida por Michel Foucault ao final do texto Outros espaços (2003, p. 421-422). O autor considera que o

Poiésis, Niterói, v. 20, n. 33, jan./jun. 2019. 
barco, esse "pedaço de espaço flutuante, lugar sem lugar, que vive por si mesmo, que é fechado em si e ao mesmo tempo lançado ao infinito do mar" - o que nos termos de Sloterdijk, corresponde à ideia de ilha absoluta - seria a própria forma da heterotopia e, desde o século XV, nossa "maior reserva de imaginação". Entretanto, seria preciso aqui cruzar as ideias de heterotopia e de linha abissal ${ }^{3}$ (SANTOS, 2007) para que um outro lado da imaginação emerja como parte do moderno empreendimento colonial assinalando meios de dominação espacial e cultural. As travessias oceânicas, seu principal vetor, alimentam-na de forma bem mais sombria, embora pintada por cores exóticas. Nesse ponto podemos dizer que o conquistador revela-se como duplo do náufrago e que se a ilha promete um novo mundo é porque ela pode ser igualmente signo do exílio e da diáspora.

Estar apartado do mundo e poder criar um novo mundo que começa do zero são, segundo Gilles Deleuze, as duas faces de um mesmo impulso implicados na ideia de ilha. Em Causas e razões das ilhas desertas (2006), o filósofo observa que "o movimento da imaginação das ilhas retoma o movimento da sua produção", aproximando mitologia e ciência. A ocupação de ilhas, diz ele, só se faz sob a condição de esquecimento do conflito primordial entre os elementos água e terra, no qual estarão sempre implicados os imaginários de separação e recriação implícitos na distinção estabelecida pela geografia entre ilhas continentais, que surgem por separação acidental do continente e ilhas oceânicas, originadas por movimentos trazidos à tona por erupções vulcânicas. Portanto, não seria a ilha que convoca a ideia de utopia, mas a própria utopia que, desde Thomas Morus, assume a feição de ilha: oceânica. O mesmo paralelo poderia ser estendido entre as heterotopias de Foucault e o movimento de separação que anima as ilhas continentais.

Assim, a estranheza especular que rege as relações entre uma e outra parece encontrar na Ilha do Fundão importante ponto de adensamento, superpondo imaginários geográficos, arquitetônicos e urbanísticos aos institucionais e políticos, dos quais não se separam. O fato de ser uma ilha artificial, construída sobre pequeno grupo de ilhas naturais aterradas na Baía de Guanabara a fim de abrigar um campus universitário, só reforça seu caráter de "contorno contornado", o que nos leva a indagar possíveis afinidades entre universidade e ilha. 
Na moderna ideia de cidade universitária, vemos a expressão de um desejo fadado a nunca se completar, animado pela pretensão universalista e utópica de tentar reunir em um único sítio o conjunto do saber ou, ao menos, as condições de sua produção. Oscilando entre microcosmo e totalidade, destacada e protegida da cidade real por condições urbanísticas e topográficas, podemos reconhecer nesta distribuição espacial princípios que regem as heterotopias foucaultianas ${ }^{4}$. Tais desígnios parecem se naturalizar na redundância da expressão geográfica da ilha. Ao mesmo tempo, se encontram potencializados por características da arquitetura modernista, cujo paradigma, segundo Roberto Conduru (2017), é também insular, pois recorta espaços assim como a própria história. Na escassez de diálogo com o preexistente e com o contíguo, a imposição de um corte radical não se sustenta no tempo, trazendo consigo o germe da ruína.

Acompanhar a crítica à arquitetura modernista no Brasil permite pensar certa solidariedade entre projeto moderno de país e projeto de universidade no Brasil. Hoje, diante do avançado estado de ruína arquitetônica das instalações da um dia sonhada Universidade do Brasil, esquecemos o quanto seu projeto esteve imbricado na gênese da arquitetura moderna brasileira, cujo marco inaugural foi a construção do prédio do Ministério da Educação e Saúde (1936) do governo Vargas, atual Palácio Capanema. O fato de que nenhum dos projetos de cidade universitária elaborados por Marcello Piacentini, Le Corbusier e Lucio Costa tenha saído do papel revela como a vontade de superação do passado colonial e de inserção do país na modernidade era atravessada por antagonismos entre forças diversas. A intelectualidade dentro e fora do governo (o poeta Carlos Drummond de Andrade e Anísio Teixeira, líder do grupo da Escola Nova, são nomes a serem aqui lembrados), correntes oligárquicas, Igreja e Forças Armadas disputavam o protagonismo na formação da juventude brasileira. A preocupação era afastá-la dos perigos do comunismo. As intensas disputas políticas e ideológicas assumiram diferentes partidos estéticos, embora hoje se possa perceber mais afinidades entre os projetos arquitetônicos do que seus autores gostariam de supor.

Enfrentando muitas dificuldades, a construção do campus se inicia nos anos 1950, mas sua execução se arrasta, anunciando a descaracterização dos dias atuais ${ }^{5}$. As doze pos-

Poiésis, Niterói, v. 20, n. 33, jan./jun. 2019. 
síveis locações e as quase quatro décadas que se somam entre aquele ano de 1936 e a inauguração da UFRJ em 1972, já em pleno regime militar, só confirmam as hesitações sobre o modelo de universidade a ser irradiado para o resto do Brasil e as dificuldades de assentamento e concretização do lugar da educação pública e gratuita no Brasil, movendo-se entre projeto oligárquico e regime autoritário, utopia e inacabamento. Neste momento crítico de ataques à universidade movidos por interesses neoliberais, este breve retrospecto permite-nos entrelaçar alguns fios que nos ajudam a não confundir ruína modernista com o arruinamento imposto às condições da educação no país.

Devemos o reconhecimento de uma dívida social de longa data e da necessidade de acoIhimento de reivindicações emergentes à política de cotas sociais implantada na universidade pública durante os governos de Lula e Dilma. O desafio a uma revisão dos mecanismos e tradições de uma concepção elitista de universidade se impõe a todos os que dela participam. Neste sentido, pode-se dizer que o projeto DESILHA é tributário dessa busca. O que se pode discernir nessa paisagem? Ou como diz Derrida (1999, p.124): "A Universidade em vista de quê? Qual é a vista, quais são as vistas da Universidade? Ou ainda: o que se vê desde a Universidade, quer se esteja simplesmente nela ou à sua borda, quer, indagando sobre sua destinação, se esteja em terra ou ao largo."

A figura da ilha insiste em um mundo de redes e fluxos informacionais intensos, pois oferece-nos contornos a partir dos quais algo diferente, no sentido da alteridade, começa a se fazer presente. O paradigma insular permite perceber possibilidades enunciativas de uma gama de histórias e vozes dissonantes. Constituídas de "outro modo que não a modernidade" (BHABHA, 1998, p. 26), as culturas que se produzem pelos que vivem ao largo, isto é, às suas margens, são as únicas capazes de inscrever suas histórias e vidas no imaginário da cidade, forçando o redesenho de mapas e a reescrita da memória coletiva.

Hoje, o Complexo da Maré margeia a Ilha do Fundão em toda a sua extensão, espelhando não apenas sua forma em reverso. No nome - maré - persiste a lembrança do conflito primordial entre terra e água ao qual se soma a luta dos excluídos do continente, em sua 


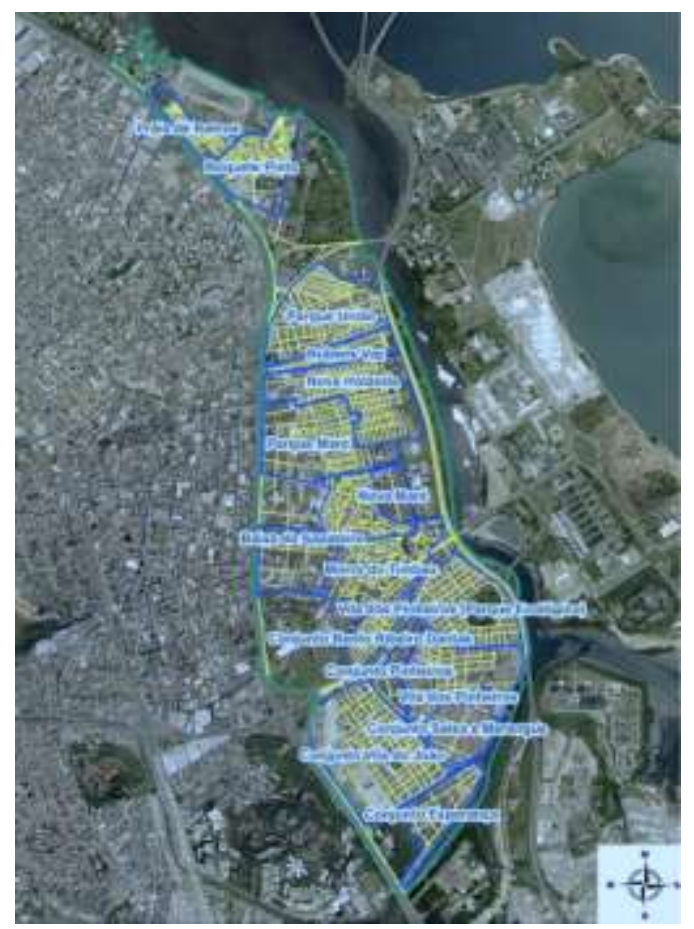

Fig. 1 - Bairro da Maré com destaque para 16 comunidades.

Mapa produzido por Luana Caruso Nóbrega - Programa de Desenvolvimento Local da Maré - Rede de Desenvolvimento da Maré/ (https://www.maxwell.vrac.puc-rio.br/21758/21758_6.PDF)

Poiésis, Niterói, v. 20, n. 33, jan./jun. 2019. 
maioria migrantes do desterro, por um solo no qual fincar suas antigas palafitas. Em área equivalente aos $5 \mathrm{~km} 2$ da ilha, distribuída em 16 favelas com diferentes histórias e características socioespaciais, está confinada a população de uma cidade média brasileira, da qual $10 \%$ é analfabeta e apenas $2 \%$ frequenta a universidade. Daquele território sujeito à violência da polícia e de grupos ligados ao tráfico e à milícia, emergem potências de invenção tornadas invisíveis pela linha abissal traçada entre Maré e Fundão, Maré e cidade. São "vidas-linguagem" (BENTES, 2015, p. 93) que reivindicam direitos de existência e expressão. Propõem novas redistribuições simbólicas ao contrapor-se às narrativas hegemônicas que insistem em reservar os papéis de vítima ou criminoso aos jovens favelados.

\section{Entre ilha e cidade: desilha}

Não por acaso, podemos considerar como ação inaugural do projeto DESILHA a realização de uma travessia de barco entre a Ilha do Fundão e a vizinha Maré em maio de 2016, por ocasião do Simpósio Utopias ${ }^{6}$. Proposição aparentemente absurda, senão inusitada, quando se sabe que a ilha está ligada ao continente por pelo menos quatro acessos viários, entre os quais um pode ser percorrido a pé. Navegar o contorno da ilha para desembarcar na Maré seria apenas um gesto paródico se esse trajeto não nos permitisse pensar quantas camadas de ficção e de realidade compõem uma experiência, quanto de passado e de futuro se friccionam em uma travessia; se não nos permitisse experimentar na pele a diferença sensível entre territórios imediatamente vizinhos; se atravessando aquelas ruas e vielas não fossemos atravessados por elas, pelo medo e vulnerabilidade diante do surgimento de um "caveirão" - carro blindado da Polícia Militar do Estado do Rio de Janeiro usado em incursões nas favelas - em um dos inúmeros e cotidianos momentos de irrupção de uma guerra instantânea e insidiosa. Desembarcamos no píer improvisado sob um daqueles viadutos, em meio à comunidade de pescadores de uma tradição em vias de desaparecimento, a poucos metros do Hospital Universitário, não como conquis- 
tadores ou náufragos, mas em busca de outras possibilidades de encontro e aprendizado: vibração e vibratibilidade como pressupostos para a construção de alianças.

Na origem do projeto DESILHA está a prática docente junto à linha de pesquisa em Linguagens Visuais do Programa de Pós-Graduação em Artes Visuais (UFRJ), dirigida à formação teórico-prática de artistas contemporâneos. Considerando que o paradigma insular ancora profundamente a noção de trabalho em arte sob o signo do sujeito-autor, da moldura e do cubo branco/caixa preta, propomos convocar a criação artística ao debate coletivo, colocando-a em situação, a fim de provocar um estado de fricção com o entorno. Ao longo dos cursos semestrais ministrados desde 2014 por Livia Flores e Ronald Duarte, ambos artistas, e contando, a partir de 2017, com a participação de Michelle Sommer, pesquisadora, crítica de arte e curadora, fomos re-conhecendo o galpão onde trabalhamos, misto de ateliê, sala de aula e local de exposição, mas também a universidade, a ilha e a cidade, através dos deslocamentos entre diversas posições e da proposição de ações, transformando a palavra desilha em verbo e convite a mover-se além dos perímetros demarcados da arte e do seu ensino formal.

Refletindo sobre mudanças de paradigma na crítica de arte movidos por posicionamentos feministas, Jane Rendell afirma que "onde estou faz diferença para pensar quem eu posso ser e o que eu posso saber". (citada por DOHERTY, 2009, p. 22) Não é de se estranhar que a proposição de atenção ao lugar emerja do movimento feminista; através dele, noções como privado e público passam a ser problematizadas por diferenças de gênero, desfazendo limites tão nítidos quanto pretensamente neutros. O redesenho das linhas de poder, de seus efeitos e também de suas brechas, parte da observação do lugar.

Nos anos 1920, vanguardas surrealistas e dadaístas lançavam-se à experiência do lugar em busca de estranhamentos da ordem cotidiana invertendo o sentido dos procedimentos de pesquisa de antropólogos junto a civilizações consideradas selvagens. Décadas depois, a prática retomada por situacionistas passa a promover exercícios de deriva como formas de conhecimento e de apreensão psicogeográfica.

Poiésis, Niterói, v. 20, n. 33, jan./jun. 2019. 
Embora sem filiação a tais movimentos, práticas de deslocamento e cartografias do lugar são adotadas nos cursos como parte fundamental da proposta de encontro com a alteridade, onde a percepção de zonas de tensão ou de liberdade pode ser ponto de partida para experimentações. Interessa-nos aqui a figura do cartógrafo que Suely Rolnik delineia, mais próxima de um antropófago do que de um antropólogo: "Deixa seu corpo vibrar todas as frequências possíveis e fica inventando posições a partir das quais essas vibrações encontrem sons, canais de passagem, carona para a existencialização". (1998, p. 33)

Outro elemento importante disso que se poderia nomear "trabalho de campo" são as múltiplas possibilidades de registro, que permitem não apenas elaborar experiências vividas como podem fornecer elementos para a constituição de obras e de proposições artísticas, sem necessariamente apelar para o documental. Pois como diz ainda Rolnik, "tudo o que der língua para os movimentos do desejo, tudo o que servir para cunhar matéria de expressão e criar sentido, para ele [cartógrafo] é bem-vindo. Todas as entradas são boas, desde que as saídas sejam múltiplas". (1998, p. 33) Nessa direção, os mais diversos meios de expressão são acolhidos e o acompanhamento dos processos se faz mediante apresentação e discussão coletiva dos trabalhos. Consideramos que ao final dos cursos torna-se importante encontrar formas de acontecimento das obras e proposições em diálogo com públicos externos ao projeto. Estas ocasiões apresentam-se como oportunidade de maturação dos trabalhos desenvolvidos, sejam eles individuais ou coletivos.

Em 2016, o evento Campo de Provas Open Air, realizado às vésperas das Olimpíadas, foi a forma proposta para acolher ações efêmeras ao ar livre, desenvolvidas ao longo do semestre e realizadas no campus da Ilha do Fundão. Considerando a importância de um revezamento plástico-discursivo, como propõe Ricardo Basbaum (2008), esta programação integrou o DESILHA 2016_Seminário de pesquisas em arte e cidade, realizado na Casa França-Brasil em julho daquele ano. O convite à fala e ao encontro, a pensar ilhas desde os lugares mais recônditos do corpo aos espaços abertos da imaginação, contou com mais de 30 interlocutores entre artistas e pesquisadores oriundos dos campos das artes visuais, da literatura e da educação, da crítica e da curadoria, do teatro e das ciências sociais, ativistas e estudantes. Em especial, o seminário marcou a abertura de canais de diálogo com artistas e ativistas da Maré, ampliando o escopo da pesquisa e trazendo novos aspectos para a discussão. 


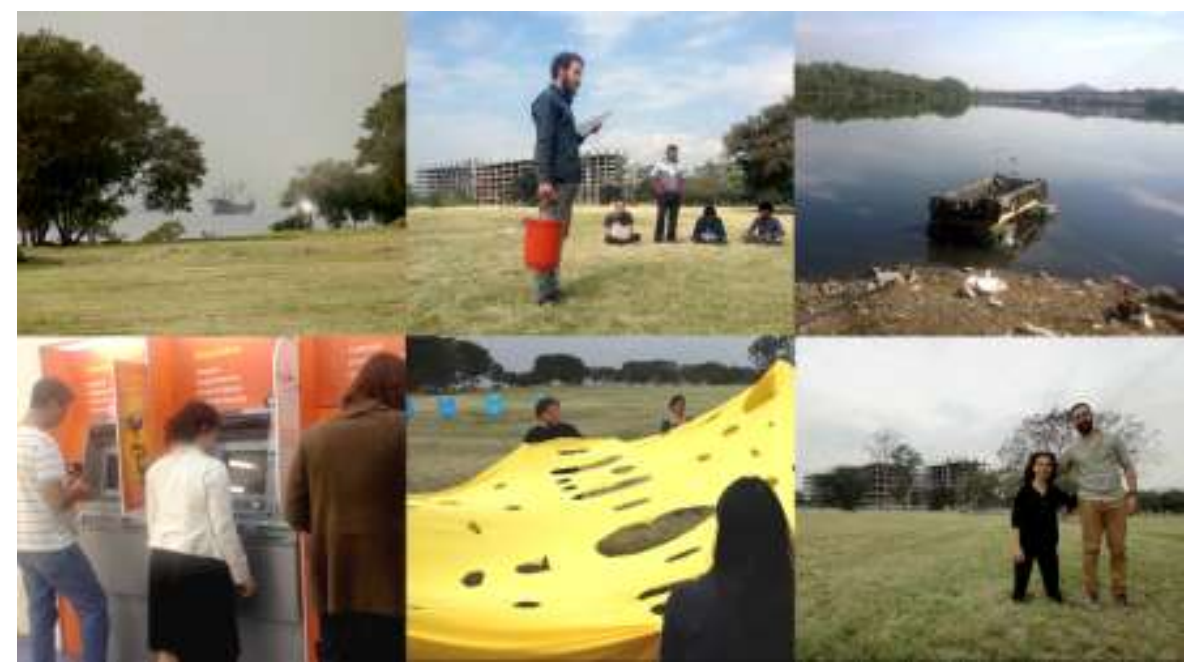

Fig. 2 - Imagens do evento Campo de Provas Open Air, campus do Fundão, 2016.

(Fonte: acervo DESILHA)

Poiésis, Niterói, v. 20, n. 33, jan./jun. 2019. 
Em 2017, ousando deixar a ilha e adentrar pontos críticos da cidade, o curso percorreu lugares violentamente impactados pelas reformas urbanas que aconteceram no Rio de Jáneiro entre a realização dos dois megaeventos Copa do Mundo (2014) e Olimpíadas (2016). Condição e motor para os deslocamentos propostos foi o encontro com interlocutores artistas, ativistas e locais, ao final de cada trajeto. Além dos percursos realizados na Ilha do Fundão - especialmente em sua orla que acumula impressionantes quantidades de lixo da Baía de Guanabara - quatro práticas de movimento impulsionaram estados de invenção que culminaram em uma ação-evento-exposição.

A primeira travessia ocorreu na Vila Autódromo, comunidade urbana no bairro de Jacarepaguá que resistiu parcialmente às atrocidades dos processos de remoções impostas por políticas de urbanização excludentes coordenadas pelo então prefeito do Rio de Janeiro, Eduardo Paes, para a construção do Parque Olímpico em 2016. Em 2013, a prefeitura da cidade deu início a um processo para desalojar os habitantes daquele bairro, lar de mais de 600 famílias que, mesmo possuindo o direito à terra, foram duramente violentadas e expulsas do território. Nesse contexto, 20 famílias resistiram às remoções e uniram-se para, junto a outros agentes que acompanharam o processo, criar o Museu das Remoções, onde obras são as pessoas e suas memórias de resistências nas lutas sociais urbanas e direito ao território e à habitação, configurando um espaço que expressa a própria dinâmica de cuidado e luta pública coletiva.

A segunda travessia foi realizada na linha de trem da Central do Brasil que conecta o centro às periferias da zona norte da cidade. Pouco frequentado por artistas e cidadãos oriundos das classes média e alta cariocas, o uso do trem como meio de transporte público foi tanto oportunidade de observação e de experiência das distâncias da cidade como palco para a realização de trabalhos. Ao final do trajeto, a visita ao Espaço Citrus, da artista e performer Laís Castro, permitiu ao grupo acessar potencialidades e entraves a práticas artísticas na periferia. 


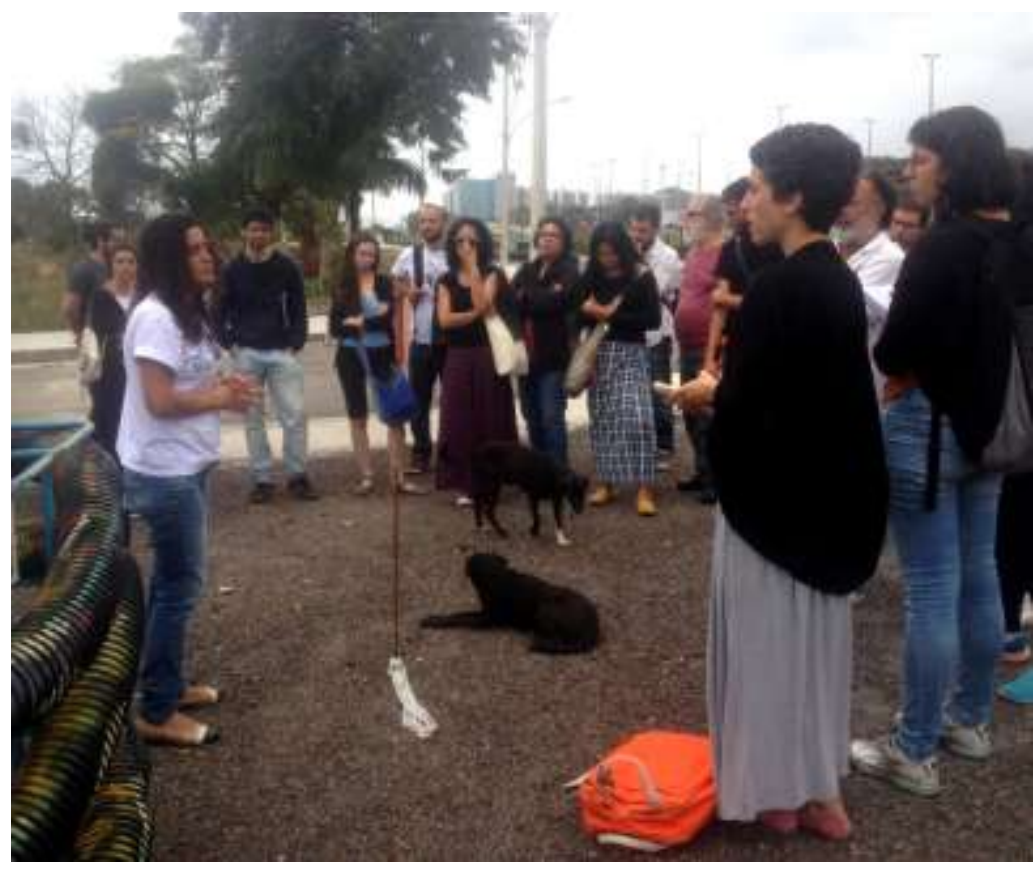

Fig. 3 - Vila Autódromo na ocasião do encontro (Fonte: acervo DESILHA)

Poiésis, Niterói, v. 20, n. 33, jan./jun. 2019. 
A terceira travessia - que transbordou na proposição para o ano de 2018 - ocorreu no entorno imediato da Ilha do Fundão e mergulhou no Complexo da Maré, tendo por anfitriões e guias Davi Marcos, Josinaldo Medeiros e Naldinho Lourenço, integrantes do coletivo NA Favela (Núcleo Audiovisual Favela) - produtora colaborativa audiovisual localizada na Vila do Pinheiro.

A quarta e última travessia foi realizada na Aldeia Maracanã. Situada na área conhecida como o Antigo Museu do Índio, o território é uma Aldeia Indígena urbana, localizada no antigo prédio do Museu do Índio, no entorno do estádio do Maracanã. Em 2013, a Aldeia Maracanã foi violentamente ocupada por forças policiais para expulsar os indígenas habitantes do local - cerca de 60 pessoas - para a realização das obras para a Copa do Mundo de 2014. Nesse contexto, o asfalto impôs-se sobre os pés de milho, abóbora, mandioca, mamão, goiaba e plantas medicinais que eram cultivadas no local.

Resistindo às remoções, o território tornou-se referência para os movimentos políticos quando 10 famílias indígenas oriundas de diversas etnias retornaram ao antigo imóvel no final de 2016 e esforçam-se para manter o local habitável de acordo com as tradições nacestrais. Mobilizações recentes clamam ao poder público a transformação da área em uma pluriversidade indígena, como propõem os militantes da causa. Em ações poéticas que integraram os habitantes locais, práticas do Teatro do Oprimido, método teatral que reúne exercícios, jogos e técnicas propostos pelo teatrólogo Augusto Boal (1931-2009), foram propostas por um dos participantes do curso, Lucas Sargentelli, em parceria com Cris Ribas, como instrumentos de emancipação política e transformação social através da interação e diálogo.

Como porto de chegada de 2017, a ação-evento-exposição foi um fechamento das ações e abertura para outras partidas, realizada no Galpão da Pós/EBA-UFRJ e no Saracura (2016-2018), espaço independente e experimental localizado nas proximidades do Cais do Valongo, sítio arqueológico que recebeu milhares de africanos escravizados. Intitulada Subur Zona de Conforto a partir de trabalho de um dos integrantes do curso, Thiago Ortiz, a mostra reuniu proposições artísticas desenvolvidas durante o semestre, contando 
com a presença de convidados: Elilson apresentou a ação performativa Gota, desenvolvida no curso do semestre anterior; e o coletivo NA Favela exibiu Pescadores da Maré, filme que aborda a luta pela subsistência da comunidade pesqueira da Maré, trazendo a questão da violência e sobrevivência a debate.

Após esta extensa série de deslocamentos, extravasando em alguns casos os limites do curso pela mobilização ou continuidade de engajamentos e iniciativas pessoais com os interlocutores, interessou-nos em 2018 concentrar as atividades em um único lugar, a Maré. Propondo aproximar bordas entre ilha e continente, a palavra experiência (EX fora / PERI limite, perímetro / ENTIA ação de aprender ou conhecer) seria mote para deslocamentos além dos perímetros conhecidos da arte, do ensino acadêmico e do território ocupado pela universidade. A data de início do curso coincidiu com o dia seguinte ao assassinato da vereadora Marielle Franco, caindo como uma bomba sobre toda a cidade e atingindo especialmente nossos parceiros do NA Favela. O trânsito e a vivência alternada entre territórios tão próximos quanto díspares impactaram e geraram discussões produtivas sobre as relações entre arte e campo social. Neste contexto, a leitura do texto Favela da Maré ou o milagre das palafitas, de Lygia Pape (2018), forneceu-nos o argumento para a realização de um segundo seminário ${ }^{7}$, estruturado a partir de quatro eixos: arqueologias, margens, arquiteturas e imantações.

$\mathrm{Na}$ atual edição, o curso volta-se para a área central da cidade, identificando ilhas urbanas centrais e conectando-se com o projeto Plataforma de Emergências ${ }^{8}$ e Lanchonete <> Lanchonete - Ocupação Bar Delas, capitaneado pela artista Thelma Vilas Boas ${ }^{9}$. Dando continuidade à publicação dos Cadernos Desilha (2017), as discussões relativas às atividades realizadas nos anos de 2018 e 2019 estarão presentes em um segundo livro, atualmente em desenvolvimento.

As ações propostas pela plataforma DESILHA discutem cidadania e ativismo, englobam percepções sobre multiculturalismo e interculturalidade na cidade e tomam o espaço urbano como impulso para a construção de narrativas e de ações, aderindo o lugar da universidade ao contexto social imediato da cidade. Para, quiçá, novas e outras navegações, em um futuro possível, porvir.

Poiésis, Niterói, v. 20, n. 33, jan./jun. 2019. 


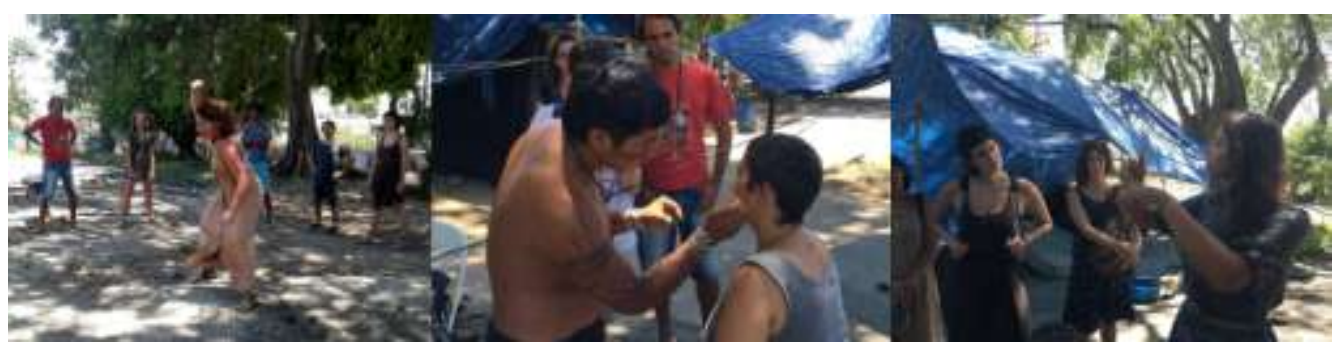

Fig. 4 - Imagens do encontro na Aldeia Maracanã. (Fonte: acervo DESILHA) 


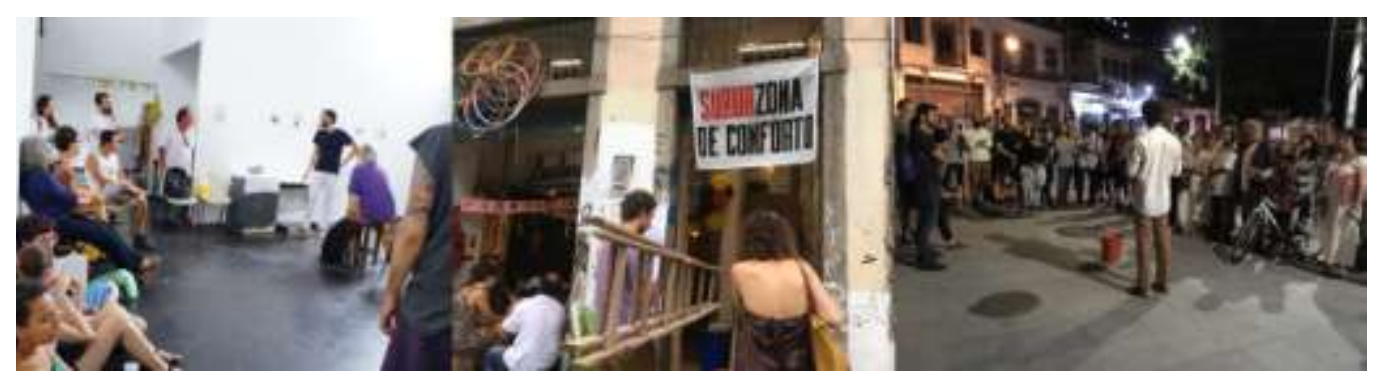

Fig. 5 - Imagens do evento-exposição Subur Zona de Conforto no Galpão da Pós e no Saracura. (Fonte: acervo DESILHA)

Poiésis, Niterói, v. 20, n. 33, jan./jun. 2019. 


\section{Notas}

1 O presente texto retoma algumas questões apresentadas por Livia Flores em "Cartas de navegação", Cadernos Desilha e em "Ilha, Desilha, travessias", Anais da ANPAP, 2017.

2 Surroundings surrounded é título de uma exposição do artista dinamarquês Olafur Eliasson, que o filósofo toma de empréstimo.

3 Segundo Santos (2007), linhas abissais não param de desenhar novos territórios coloniais desde sua primeira manifestação cartográfica, o Tratado de Tordesilhas. Elas atravessam o pensamento moderno provocando divisões de tal ordem que há sempre um "outro lado da linha que desaparece como realidade, torna-se inexistente e é mesmo produzido como inexistente".

${ }^{4}$ Entre eles, Foucault enumera: 1. seus modos de funcionamento respondem a demandas da sociedade, que podem se modificar com o tempo; 2. num único lugar justapõem-se vários espaços (ilha, jardim, biblioteca, arquivo, laboratório, escola); 3. heterotopias são também heterocronias, isto é, recortam o tempo de forma diferente, por vezes acumulando-o sob a forma de arquivo; 4. demarcam limites e procedimentos de inclusão e exclusão; 5. sua função com relação ao espaço restante se desenvolve por contraste, ora como espaço de ilusão tão intenso que coloca em questão a própria realidade do mundo real, ora como ordenação extrema de forma a compensar o caos vigente no entorno.

${ }^{5}$ À frente do Escritório Técnico da Universidade do Brasil, o arquiteto Jorge Moreira assume o projeto que mantém algumas configurações dos planos de Costa e Le Corbusier para a Quinta da Boa Vista.

${ }^{6}$ A ação foi realizada a convite da Professora Alessandra Vannucci, uma das organizadoras do Simpósio Utopias, Galpão Bela Maré, maio de 2016.

${ }^{7}$ Desilha 2018_20 seminário nacional de pesquisas em arte e cidade realizou-se nos dias 17 e 18 de outubro de 2018 no Centro Municipal de Artes Hélio Oiticica, com conferencistas convidados e apresentações de comunicações selecionadas via chamada pública.

${ }^{8}$ O programa de extensão Plataforma de Emergência é uma iniciativa do Centro Municipal de Arte Hélio Oiticica, vinculado à Secretaria Municipal de Cultura do Rio de Janeiro, em parceria com a UFRJ, UFF, Unirio, Uerj e PUC, através de seus programas de pós-graduação nas áreas das artes visuais, artes cênicas, filosofia, comunicação social, sociologia, antropologia e psicologia. A cada semestre, com o deslocamento das turmas para o CMAHO, são também oferecidas vagas para a comunidade em geral, ampliando-se a atuação acadêmica da universidade para além-muros.

${ }^{9}$ O projeto vem sendo gestado desde 2015. Em 2017, ocupou o Saracura e em abril de 2018 acoplou-se ao Bar Delas, uma ocupação feminista liderada por Kriss Coiffeur.

\section{Referências}

BASBAUM, Ricardo. R. Você gostaria de participar de uma experiência artística? (+ NBP). Tese de doutorado. Universidade de São Paulo, 2008. 
BENTES, Ivana. Vidas-linguagens: deslocamentos subjetivos e reservas de mundo. In Mídia-multidão: estéticas da comunicação e biopolíticas. Rio de Janeiro: Mauad X, 2015.

BHABHA, Homi K. O local da cultura. Belo Horizonte: Editora UFMG, 1998.

CONDURU, Roberto. Arquitetura como ilha. In FLORES, Livia; SOMMER, Michelle (Org.). Cadernos Desilha. Rio de Janeiro: Programa de Pós-Graduação em Artes Visuais (PPGAVEBA-UFRJ); Editora Circuito, 2017.

DELEUZE, Gilles. Causas e Razões das Ilhas Desertas. In A Ilha Deserta e outros textos. São Paulo: Iluminuras, 2006.

DERRIDA, Jacques. O Olho da Universidade. São Paulo: Estação Liberdade, 1999.

DOHERTY, Claire. Situation. Documents of Contemporary Art. Londres: Whitechapel Gallery; The MIT Press, 2009.

FLORES, Livia; SOMMER, Michelle (Org.) Cadernos Desilha. Rio de Janeiro: Programa de Pós-Graduação em Artes Visuais (PPGAV-EBA-UFRJ); Editora Circuito, 2017. Disponível em http://editoracircuito.com.br/website/wp-content/uploads/2017/12/DESILHA-mioloweb.pdf

FOUCAULT, Michel. Outros espaços. In Ditos e escritos III. Rio de Janeiro: Forense Universitária, 2003

PAPE, Lygia. Favela da Maré ou milagre das palafitas. Revista Arte \& Ensaios, Rio de Janeiro (PPGAV-EBA-UFRJ), n. 36, 2018.

ROLNIK, Suely. Cartografia sentimental In Roteiros. Roteiros. Roteiros. Roteiros. Roteiros. Roteiros. Roteiros (catálogo da XXIV Bienal de São Paulo). São Paulo: Fundação Bienal, 1998 , p. 33.

SANTOS, Boaventura de Souza. Para além do pensamento abissal: das linhas globais a uma ecologia dos saberes. Novos Estudos, São Paulo (Cebrap), n. 79, 2007.

SLOTERDIJK, Peter. Esferas III. Espumas. Esferologia plural. Madri: Ediciones Siruela, 2006.

Poiésis, Niterói, v. 20, n. 33, jan./jun. 2019. 